\title{
Changes of Cell Adhesion Molecules and T Cell Subset Populations in Acute Myeloid Leukemia Patients Undergoing Intravenous Administration of Cytarabine Supplemented with Idarubicin
}

\author{
Jinhua Piao, ${ }^{1}$ Didi Wang, ${ }^{2}$ Siying Pei $\mathbb{C}^{2},{ }^{2}$ Tangdong Ge, ${ }^{2} \mathrm{Jing} \mathrm{Li}^{2}$ and Pengxia Zhang $\mathbb{D}^{1}$ \\ ${ }^{1}$ Key Laboratory of Microecology-Immune Regulatory Network and Related Diseases, School of Basic Medicine, \\ Jiamusi University, Jiamusi, China \\ ${ }^{2}$ Biochemistry Teaching and Research Office, School of Basic Medicine, Jiamusi University, Jiamusi, China
}

Correspondence should be addressed to Pengxia Zhang; pengxiaz@jmsu.edu.cn

Received 24 December 2021; Accepted 13 January 2022; Published 8 February 2022

Academic Editor: Weiguo Li

Copyright (c) 2022 Jinhua Piao et al. This is an open access article distributed under the Creative Commons Attribution License, which permits unrestricted use, distribution, and reproduction in any medium, provided the original work is properly cited.

Objective. The present study aimed at investigating the efficacy and safety of intravenous administration of cytarabine supplemented with idarubicin in treating acute myeloid leukemia (AML) patients undergoing first attack and its effects on serum levels of cell adhesion molecules, cytokines in response to inflammation, and T cell subset populations in acute myeloid leukemia (AML) patients undergoing first attack. Methods. A total of 88 AML patients eligible for inclusion and exclusion criteria participated in the study and were randomly assigned into the control group $(n=44)$ in which the patients received intravenous administration of cytarabine and daunorubicin and the study group $(n=44)$ in which the patients received intravenous administration of cytarabine and idarubicin. Clinical response, incidence of adverse reactions, and quality of life 3 months after therapy were evaluated. Soluble intercellular adhesion molecule-1 (sICAM-1), soluble vascular cell adhesion molecule-1 (sVCAM-1), IL-10, and IL-35 were measured by ELISA methods. Phenotypic characteristics of T cell subsets including CD4 ${ }^{+}$, $\mathrm{CD} 8^{+}, \mathrm{CD} 4^{+} \mathrm{IL}-10$ Tregs, and $\mathrm{CD} 4^{+} \mathrm{CD} 25^{+} \mathrm{CD} 127^{-} \mathrm{Foxp}^{+}{ }^{+}$Tregs were analyzed by flow cytometry. Results. The clinical response rate of the study group was better than that of the control group $(65.91 \%$ vs. $45.45 \%)(P<0.05)$. After treatment, the study group revealed significantly lower levels of sICAM-1, sVCAM-1, IL-10, and IL-35, a lower proportion of Tregs, a higher rate of CD4 ${ }^{+} /$ $\mathrm{CD}^{+} \mathrm{T}$ cells, along with increased scores of the Karnofsky Performance Scale (KPS) compared with the control group $(P<0.05)$. The incidence rate of adverse reactions in the study group was lower than that in the control group $(34.09 \%$ vs. $61.36 \%)(P<0.05)$. Conclusion. These findings demonstrate that intravenous administration of cytarabine supplemented with idarubicin can improve the immune function and quality of life of AML patients, and this combination drug therapy is effective and safe for AML.

\section{Introduction}

Acute leukemia is classified into acute myeloid leukemia (AML) and acute lymphocytic leukemia according to the presence of different damaged cells [1]. AML is a malignant clonal disease characterized by changes in normal hematopoietic cells, leading to the proliferation of immature progenitor cells and inhibition of cell differentiation. Immature progenitor cells spread through blood to various parts of the body [2]. AML is commonly seen in adults, especially for these diagnosed at a median age of 68 years, accounting for up to $80 \%$ of acute leukemia [3]. AML incidence is positively correlated with age. It was reported about 1.3 cases out of 100 thousand people had the disease and the age was below 65 years old, and 12.2 cases, who aged over 65 years, out of 100 thousand people were subject to the disease [4]. Although the progress of AML treatment is beneficial to significant improvement in the prognosis of young patients, AML is associated with variable prognosis and high mortality. The 5 -year overall survival was $40-50 \%$ 
in younger adults with new diagnosed AML [5]. The prognosis of the elderly, who account for the majority of new cases, is still very poor. $20 \%$ of elderly patients died of the disease after 2 years of diagnosis [6], and up to $70 \%$ of patients aged 65 or over cannot survive within 1 year after diagnosis [7].

The prognosis of AML is closely related to cytogenetic results and molecular abnormalities at the time of diagnosis. These two factors can predict the complete remission rate, disease-free survival, recurrence risk, and overall survival $[8,9]$. Myeloperoxidase activity in fibroblasts found by immunophenotypic and cytochemical analyses or analysis of immunophenotypic surface molecules has been proved to be a specific diagnosis of AML [2]. AML is considered to be a malignant disease with immune dysfunction. The basic role of immune microenvironment in the prognosis of leukemia has been confirmed in many studies $[10,11]$. T cells are derived from bone marrow pluripotent stem cells, and the key role of $\mathrm{T}$ cells has been recognized in antigen-specific recognition and elimination of malignant cells [12]. Activation of the immune response of cytotoxic $\mathrm{T}$ cells is very important for the treatment of viral diseases and tumors [13]. The presence of chronic infection, tumor, and cancer is associated with immune dysfunction. $\mathrm{CD}^{+}, \mathrm{CD}^{+}$, and $\mathrm{CD}^{+} \mathrm{T}$ cells are involved in immune response and confirmed as effective biomarkers in viral infectious diseases and inflammatory disorders $[14,15]$. Regulatory T cells, termed as Tregs, represent a subpopulation of $\mathrm{CD} 4^{+} \mathrm{T}$ cells and can inhibit the immune response, which have three classifications according to the cytokines they secrete, including naturally occurring $\mathrm{CD} 4{ }^{+} \mathrm{CD} 25^{+} \mathrm{Foxp}^{+}$Tregs, interleukin 10 (IL-10)-producing Tregs, and transforming growth factor- $\beta$ (TGF- $\beta$ )-producing Tregs [16]. IL-35, a member of the IL-12 family, is secreted by Treg cells and contributes to the immunosuppressive activity of Tregs, rather than acting in an immunostimulatory or proinflammatory manner [17]. Vascular cell adhesion molecule-1 (VCAM-1) is also known as CD106, and intercellular adhesion molecule-1 (ICAM-1) is also known as CD54, are transmembrane glycoprotein. They are induced by a variety of cytokines, such as tumor necrosis factor $\alpha$ (TNF- $\alpha$ ), IL-1, and interferon $\gamma$, and usually expressed in endothelial cells and immune cells [18]. At present, chemotherapy regimens of cytarabine with daunorubicin or idarubicin are the standard treatment for AML patients [19]. The purpose of this study is to investigate the changes in serum concentrations of soluble VCAM-1 (sVCAM-1), soluble ICAM-1 (sICAM-1), IL-10, and IL-35 along with $\mathrm{T}$ cell subsets including $\mathrm{CD} 4^{+}, \mathrm{CD} 8^{+}, \mathrm{CD} 4^{+} \mathrm{IL}-10$ Tregs, and $\mathrm{CD} 4^{+} \mathrm{CD} 25^{+} \mathrm{CD} 127^{-}$Foxp $3^{+}$Tregs in the newly diagnosed AML patients receiving intravenous administration of cytarabine and idarubicin.

\section{Materials and Methods}

2.1. Study Participants. From June 2019 to August 2020, 88 patients with acute myeloid leukemia (AML) were enrolled in this study. The patients were known to have AML from the diagnostic result of NCCN AML Guidelines [20] and received no treatments after the first attack. All of these patients aged 20-78 years and were confirmed to have no cognitive impairment. Unqualified patients referred to those with incomplete clinical data, less than 3 months of estimated survival time, hypersensitivity, poor treatment compliance, and who were accompanied by other clinical trials, complicated by systemic infection, organ dysfunction or malignant tumor, and subject to other hematologic disorders. The 88 patients were randomly divided into two groups. The control group $(n=44)$ included 19 males and 25 females (age range, 20-78 years; average age, $46.43 \pm 4.81$ years). The study group $(n=44)$ included 18 males and 26 females (age range, 20-77 years, average age, $45.52 \pm 4.83$ years). According to the guideline of morphology, immunology, cytogenetics, and molecular biology (MICM) classification [21], 5 cases of M1, 12 cases of M2, 8 cases of M3, 9 cases of M4, 7 cases of M5, and 2 cases of M6 were found in the control group. The study group consisted of 4 cases of $\mathrm{M} 1,13$ cases of M2, 8 cases of M3, 9 cases of M4, 8 cases of M5, and 2 cases of M6. No significant difference in these data was indicated between the two groups $(P>0.05)$. The Medical Ethics Committee of Jiamusi University approved this prospective study, and a written informed consent was obtained from all participants.

2.2. Treatment Protocols. Symptomatic treatments such as myocardial nutrition, liver protection, and stomach protection were carried out to all participants after admission. The control group received intravenous administration therapy involving cytarabine with dosage $150 \mathrm{mg} /\left(\mathrm{m}^{2} * \mathrm{~d}\right)$ and 1-2 times/d (drug approval number: H20084072, Cisen Pharmaceutical Co., Ltd., China) and a mixture of daunoblastina $\left(40 \mathrm{mg} /\left(\mathrm{m}^{2} * \mathrm{~d}\right)\right.$ and $10 \mathrm{ml}$ of $0.9 \%$ sodium chloride injection (drug approval number: H44024361, Shenzhen Main Luck Pharmaceuticals Inc., China) for successive or alternate administration once a day. The study group was treated with cytarabine which was exactly same as the control group, followed by intravenous injection of idarubicin (drug approval number: H20063284, Yatai Pharma, China) with $10 \mathrm{mg} /\left(\mathrm{m}^{2} * \mathrm{~d}\right)$ for 3 successive days. Taking 7 days as a course of treatment, both groups were followed up for 3 months after treatment.

2.3. Outcome Measures. At 7 days of treatment, the clinical response of all patients was assessed with following criteria: (a) complete remission: normal chromosome, complete remission of morphological and molecular levels, but incomplete recovery of blood cell count; (b) partial remission: less than $5 \%$ of immature cell in bone marrow, $50 \%$ decline of immature cell in the bone marrow compared with that before treatment; (c) stable disease: absence of improvement or aggravation; (d) exacerbation: progressive exacerbation, even causing death. Total response rate $=$ complete remission rate + partial remission rate. The incidence of adverse reactions, such as nausea and vomiting, bleeding, hair loss, infection (upper respiratory tract, urinary system, skin, and lung infection), was compared between the two groups. 
2.4. Enzyme-Linked Immunosorbent Assay (ELISA). Before and after 7-day treatment, $5 \mathrm{ml}$ of fasting venous blood was collected from each patient. The blood sample was placed steadily for $2 \mathrm{~h}$ prior to centrifugation $(10 \mathrm{~cm}$ centrifugal radius, $3000 \mathrm{rpm}$ for $15 \mathrm{~min}$ ). The serum levels of sICAM-1, sVCAM-1, IL-10, and IL-35 were tested by ELISA methods using commercial available kits (all purchased from R\&D systems, USA).

2.5. Flow Cytometric Analysis of T Cell Subsets. The whole heparinized blood $(200 \mu \mathrm{l})$ was added to the tubes and then centrifuged at $1300 \mathrm{rpm}$ for $8 \mathrm{~min}$, with the supernatant aspirated. The precipitates were added with $1.5 \mathrm{ml}$ PBS and centrifuged at $1300 \mathrm{rpm}$ for $8 \mathrm{~min}$ again, with the supernatant aspirated. The precipitates were added with $500 \mu \mathrm{l}$ of $1: 10$ diluted BD permeabilizing II solution and $1.5 \mathrm{ml}$ PBS and subsequently centrifuged at $1300 \mathrm{rpm}$ for $8 \mathrm{~min}$ again, with the supernatant removed. Phenotypic characteristics of T cell subsets were analyzed by the FACSCanto II triple-laser flow cytometer (BD Biosciences, USA) using fluorochromelabeled monoclonal antibody against CD4 (Cat. no. 562970, BD Biosciences), CD3 (Cat. no. 563423, BD Biosciences), CD8 (Cat. no 564492, BD Biosciences), IL-10 (Cat. no. 564053), CD25 (Cat. no. 555434, BD Biosciences), CD127 (Cat. no. 560549, BD Biosciences), and Foxp3 (Cat. no. 566526, BD Biosciences).

2.6. Karnofsky Performance Scale (KPS). The KPS is a widespread performance scoring system that is used to assess the well-being and functional status of people with illness on a scale ranging from 0 to 100 with intervals of 10 . A score of 0 indicates death and a score of 100 indicates normal function with no disease sequel. Before treatment and at 3 months after treatment, AML patients were followed up and required to fill KPS scale for evaluation of their quality of life.

2.7. Statistical Analysis. Measurement data normally distributed are described as mean \pm standard deviation and analyzed by the $t$-test, and counting data were represented by ratio and analyzed by the chi-square test in GraphPad prism software (Version 8.0). A value of $P$ less than 0.05 reflects a statistically significant difference.

\section{Results}

3.1. Intravenous Administration of Cytarabine and Idarubicin Improved Clinical Response Rate in AML Patients. After 7day treatment, the clinical response of all patients was evaluated. It was found that the study group showed higher total response rate compared to the control group. As given in Table 1, the rate in the study group and control group was $65.91 \%$ and $45.45 \%$, respectively $(P<0.05)$.

3.2. Intravenous Administration of Cytarabine and Idarubicin Declined Levels of sICAM-1, sVCAM-1, IL-10, and IL-35 in AML Patients. The levels of sICAM-1, sVCAM-1, IL-10, and IL-35 were measured by ELISA of serum samples. The results revealed that serum levels of sICAM-1, sVCAM-1, IL-10, and IL-35 were declined significantly in AML patients following intravenous administration of cytarabine supplemented with either idarubicin or daunorubicin $(P<0.05)$, and this decrease was more evident in AML patients following intravenous administration of cytarabine supplemented with idarubicin $(P<0.05$, Figure 1$)$.

3.3. Intravenous Administration of Cytarabine and Idarubicin Improved Immune Function of AML Patients. The proportions of $\mathrm{T}$ cell subsets including $\mathrm{CD} 4^{+}, \mathrm{CD} 8^{+}, \mathrm{CD} 4^{+} \mathrm{IL}-10$ Tregs, and $\mathrm{CD} 4^{+} \mathrm{CD} 25^{+} \mathrm{CD} 127^{-}{ }^{-}$oxp $3^{+}$Tregs were analyzed by flow cytometry. It was observed that, after treatment, increased proportions of $\mathrm{CD}^{+} \mathrm{T}$ cells, $\mathrm{CD} 4^{+} \mathrm{T}$ cells, and $\mathrm{CD}^{+} / \mathrm{CD}^{+}$ratio along with decreased proportions of $\mathrm{CD}^{+}$ T cells, CD $4^{+} \mathrm{IL}-10$ Tregs, and $\mathrm{CD} 4^{+} \mathrm{CD} 25^{+} \mathrm{CD} 127^{-}$Foxp $^{+}$ Tregs were revealed in peripheral blood in AML patients following intravenous administration of cytarabine supplemented with either idarubicin or daunorubicin $(P<0.05$, Tables 2 and 3). These changes in AML patients following intravenous administration of cytarabine supplemented with idarubicin were more evident compared to those supplemented with daunorubicin $(P<0.05)$.

3.4. Intravenous Administration of Cytarabine and Idarubicin Improved Quality of Life in AML Patients. Before treatment and at 3 months after treatment, AML patients were followed up and required to fill KPS scale to reflect their quality of life. Before treatment, the scores of KPS in the study group and control group were $(75.88 \pm 3.28)$ and $(76.13 \pm 3.20)$, respectively. At 3 months after treatment, the scores of KPS in the study group and control group were $(89.81 \pm 6.43)$ and $(81.64 \pm 5.51)$, respectively. The study group and control group showed increased KPS scores after treatment ( $t=12.800, P<0.001 ; t=5.736, P<0.001)$, and this increase was more obvious in the study group $(t=6.400, P<0.001)$.

3.5. Intravenous Administration of Cytarabine and Idarubicin Led to Reduced Total Incidence Rate of Adverse Reactions in AML Patients. As given in Table 4, AML patients experienced several adverse reactions, including nausea and vomiting, myelosuppression, infection, and leukopenia after intravenous administration of cytarabine supplemented with either idarubicin or daunorubicin. Two groups of AML exhibited no significant difference in term of the incidence rates of nausea and vomiting, myelosuppression, infection, and leukopenia. However, the total incidence rate of adverse reactions in the study group was evidently lower than that in the control group (34.09\% vs. $61.36 \%, P<0.05)$.

\section{Discussion}

AML is heterologous tumor, which frequently occurs in adults. It was reported, 19,000 American populations were newly diagnosed with AML and 10,000 patients died of the disease every year [22]. The 5-year overall survival of AML is negatively related to age. It ranged $40-50 \%$ in younger 
TABLE 1: The clinical response rates of AML patients following intravenous administration of cytarabine supplemented with either idarubicin or daunorubicin.

\begin{tabular}{lcccccc}
\hline Group & Case & Complete remission & Partial remission & Stable disease & Exacerbation & Total response rate $(\%)$ \\
\hline Control group & 44 & $14(31.82)$ & $6(13.64)$ & $3(6.82)$ & $21(47.73)$ & $20(45.45)$ \\
Study group & 44 & $19(43.18)$ & $10(22.73)$ & $4(9.09)$ & $11(25.00)$ & $29(65.91)$ \\
$t$ & & & & 14.175 \\
$P$ & & & & 0.001 \\
\hline
\end{tabular}
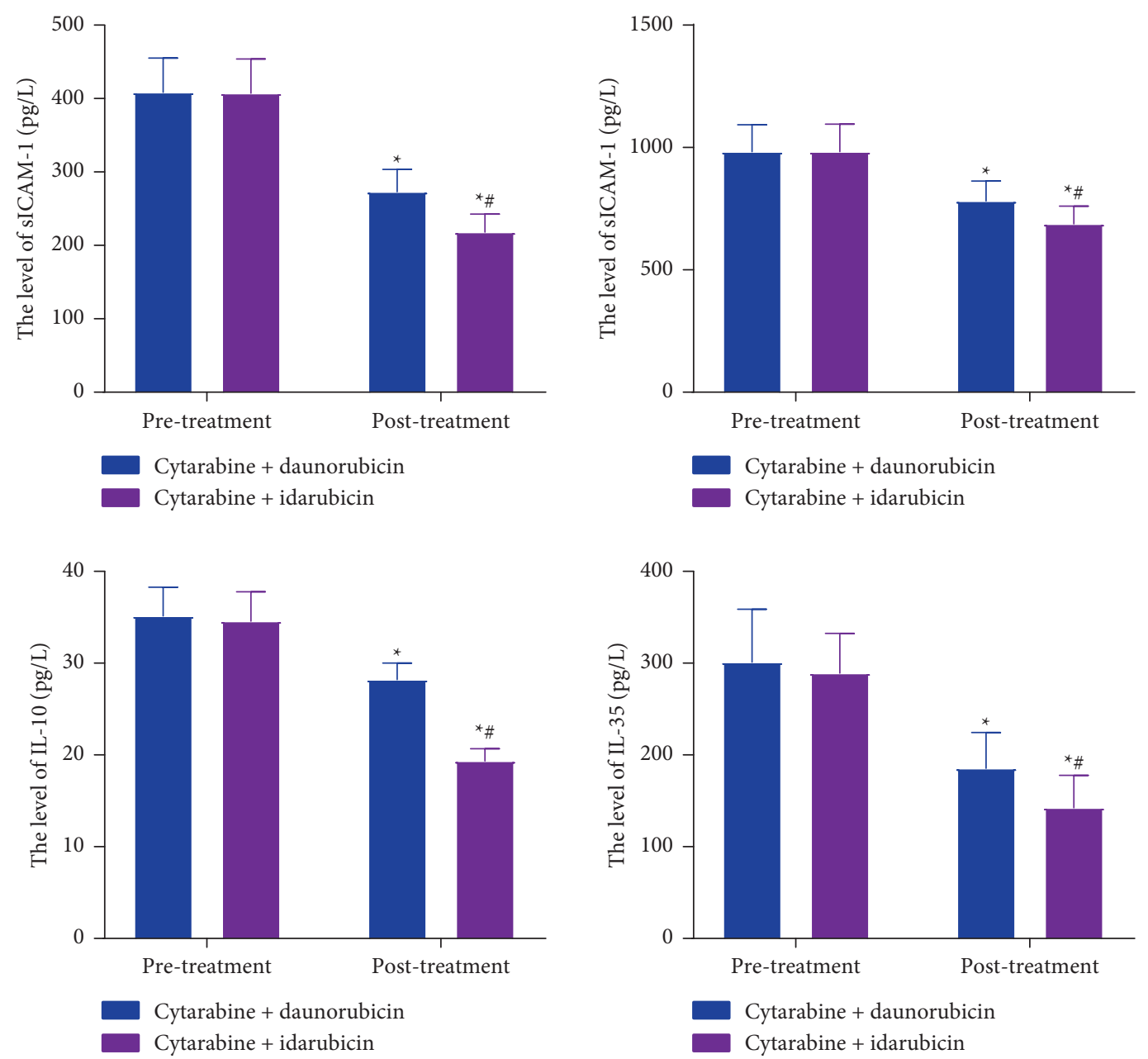

Figure 1: The levels of sICAM-1, sVCAM-1, IL-10, and IL-35 measured by ELISA of serum samples in AML patients following intravenous administration of cytarabine supplemented with either idarubicin or daunorubicin.

TABLE 2: The proportions of $\mathrm{CD} 4^{+}, \mathrm{CD}^{+}$, and $\mathrm{CD} 4^{+} / \mathrm{CD}^{+}$ratio in peripheral blood in $\mathrm{AML}$ patients following intravenous administration of cytarabine supplemented with either idarubicin or daunorubicin.

\begin{tabular}{|c|c|c|c|c|c|c|}
\hline Group & Case & Time & $\mathrm{CD}^{+}(\%)$ & $\mathrm{CD}^{+}(\%)$ & $\mathrm{CD}^{+}(\%)$ & $\mathrm{CD}^{+} / \mathrm{CD}^{+}$ \\
\hline \multirow{2}{*}{ Control group } & \multirow{2}{*}{44} & Pretreatment & $59.15 \pm 6.97$ & $30.14 \pm 3.87$ & $34.15 \pm 3.41$ & $0.79 \pm 0.08$ \\
\hline & & Posttreatment & $62.74 \pm 6.03$ & $35.87 \pm 3.72$ & $32.96 \pm 3.49$ & $1.12 \pm 0.12$ \\
\hline$t$ & \multirow{6}{*}{44} & & 8.125 & 6.193 & 0.941 & 3.618 \\
\hline$P$ & & & 0.001 & 0.007 & 0.086 & 0.029 \\
\hline \multirow{2}{*}{ Study group } & & Pretreatment & $59.17 \pm 6.99$ & $30.27 \pm 3.93$ & $34.11 \pm 3.49$ & $0.81 \pm 0.09$ \\
\hline & & Posttreatment & $73.80 \pm 8.51^{\mathrm{a}}$ & $39.91 \pm 4.76^{\mathrm{a}}$ & $29.74 \pm 2.35^{\mathrm{a}}$ & $1.39 \pm 0.19^{\mathrm{a}}$ \\
\hline$t$ & & & 12.119 & 7.374 & 5.174 & 4.396 \\
\hline$P$ & & & 0.001 & 0.001 & 0.018 & 0.027 \\
\hline
\end{tabular}

The letter a indicates $P<0.05$ compared to the control group. 
TABLE 3: The proportions of $\mathrm{CD} 4^{+} \mathrm{IL}-10$ Tregs and $\mathrm{CD} 4^{+} \mathrm{CD} 25^{+} \mathrm{CD} 127^{-}$Foxp $3^{+}$Tregs in peripheral blood in AML patients following intravenous administration of cytarabine supplemented with either idarubicin or daunorubicin.

\begin{tabular}{|c|c|c|c|c|}
\hline Group & Case & Time & $\mathrm{CD}^{+}$IL-10 Tregs (\%) & $\mathrm{CD}^{+} \mathrm{CD} 25^{+} \mathrm{CD} 127^{-}$Foxp $^{+}$Tregs (\%) \\
\hline \multirow{2}{*}{ Control group } & \multirow{2}{*}{44} & Pretreatment & $27.75 \pm 3.97$ & $23.31 \pm 3.87$ \\
\hline & & Posttreatment & $23.47 \pm 2.53$ & $19.89 \pm 1.75$ \\
\hline$t$ & \multirow{6}{*}{44} & & 6.031 & 5.341 \\
\hline$P$ & & & $<0.001$ & $<0.001$ \\
\hline \multirow{2}{*}{ Study group } & & Pretreatment & $28.11 \pm 3.63$ & $23.07 \pm 3.93$ \\
\hline & & Posttreatment & $20.40 \pm 2.04^{\mathrm{a}}$ & $18.28 \pm 1.43^{\mathrm{a}}$ \\
\hline$t$ & & & 12.280 & 7.597 \\
\hline$P$ & & & $<0.001$ & $<0.001$ \\
\hline
\end{tabular}

TABLE 4: The incidence rate of adverse reactions in AML patients following intravenous administration of cytarabine supplemented with either idarubicin or daunorubicin.

\begin{tabular}{|c|c|c|c|c|c|c|}
\hline Group & Case & Nausea and vomiting $(n, \%)$ & Myelosuppression $(n, \%)$ & Infection $(n, \%)$ & Leukopenia $(n, \%)$ & Total incidence $(n, \%)$ \\
\hline $\begin{array}{l}\text { Control } \\
\text { group }\end{array}$ & 44 & $12(27.27)$ & $5(11.36)$ & $3(6.82)$ & $7(15.91)$ & $27(61.36)$ \\
\hline $\begin{array}{l}\text { Study group } \\
t \\
P\end{array}$ & 44 & $7(15.91)$ & $2(4.55)$ & $2(4.55)$ & $4(9.09)$ & $\begin{array}{c}15(34.09) \\
16.675 \\
0.018\end{array}$ \\
\hline
\end{tabular}

patients, but only $10-20 \%$ was found in the patients over 60 years old $[19,23]$. Clinically, AML is manifested as various symptoms such as infection, fever, bleeding, anemia, and abnormal cell invasion. Most cases are in acute and severe condition, which not only affects the patient's physical condition and life quality but also endangers life. A combination of cytarabine and daunorubicin or idarubicin, also called as $7+3$ regimen, has been widely applied to most patients with newly diagnosed AML except for clinical studies [24, 25]. Idarubicin is an anthracycline antibiotic targeting tumor and cancer. It removes methoxyl at the C-4 position of daunorubicin and was prepared by Arcamone et al. in 1976 [26]. Idarubicin is a derivative of daunorubicin, which interferes with the activity of topoisomerase II and inhibits nucleic acid synthesis. Comparing to daunorubicin, idarubicin is characterized by higher lipophilicity, cell permeability, stronger immune response, and lower drug resistance [27].

Idarubicin has been widely used in clinical treatment of AML, high-risk myelodysplastic syndrome [28], hepatocellular carcinoma [29], and metastatic breast cancer [30] and turned out to be a treatment scheme to alleviate patients' symptoms. Guiu et al. [29] revealed that the patients with unresectable hepatocellular carcinoma showed better overall survival and objective response rate after interventional therapy of idarubicin-loaded beads. In our study, the patients who received idarubicin showed higher response rate and increased KPS score, suggesting combined intravenous administration of cytarabine and idarubicin was effective on prolonging life and improving life quality. Adhesion molecules on the surface of leukocytes, vascular endothelial cells, or other cells become soluble adhesion molecules after entering blood. SICAM- 1 and SVCAM- 1 are the members of immunoglobulin superfamily and participate in the migration, proliferation, and differentiation of hematopoietic cells [31]. The present study found that serum levels of sICAM-1, sVCAM-1, IL-10, and IL-35 were declined significantly in AML patients following intravenous administration of cytarabine supplemented with either idarubicin or daunorubicin $(P<0.05)$, and this decrease was more evident in AML patients following intravenous administration of cytarabine supplemented with idarubicin. The results showed idarubicin has more advantages in maintaining cellular immune balance. Zaccagni et al. also indicated that the patients with systemic lupus erythematous showed elevated levels of soluble adhesion molecule levels (VCAM-1 and ICAM-1) compared with healthy groups [32]. Low level of sICAM-1 increased cancer-related 5-year survival rate [33]. Increased level of maternal serum and vaginal fluid sVCAM-1 and sICAM-1 was found in pregnant women with preterm prelabour ruptures of membranes. These levels can be used as biomarkers to support diagnosis of the disease [34]. IL-10 exerts anti-inflammatory and immunosuppressive activities by inhibiting the production of cytokines by $\mathrm{T}$ cells [35]. Patients with adult T cell leukemia caused by human T cell leukemia virus type I infection showed elevated serum levels of IL-10 [36]. IL-35 is produced by Tregs and responsible for the suppressive activity of Tregs [37]. Tao et al. found that IL-35 was increased in peripheral blood of adult AML patients and correlated with the clinical stages of malignancy [38]. As reported by $\mathrm{Wu}$ et al., remarkable higher levels of plasma IL-35 and IL-10 were detected in newly diagnosed AML patients compared with AML patients with complete remission or healthy controls [39].

$\mathrm{T}$ cells are the main effector cells of cellular immunity. $\mathrm{CD}^{+}, \mathrm{CD}^{+}{ }^{+}$T cells, and Tregs have significant heterogeneity in cytokine expression. They produce cytokines, such as interferon- $\gamma$ and tumor necrosis factor- $\alpha$, in the immune response to mediate inflammation and remove intracellular pathogens $[40,41]$. In this study, flow cytometric analysis showed that, after treatment, increased proportions of $\mathrm{CD}^{+}$ $\mathrm{T}$ cells, $\mathrm{CD} 4^{+} \mathrm{T}$ cells, and $\mathrm{CD} 4^{+} / \mathrm{CD}^{+}$ratio along with decreased proportions of $\mathrm{CD} 8^{+} \mathrm{T}$ cells, $\mathrm{CD} 4^{+} \mathrm{IL}-10$ Tregs, 
and $\mathrm{CD} 4{ }^{+} \mathrm{CD} 25^{+} \mathrm{CD} 127^{-} \mathrm{Foxp}^{+}$Tregs were revealed in peripheral blood in AML patients following intravenous administration of cytarabine supplemented with either idarubicin or daunorubicin. This finding indicated that combined intravenous administration of cytarabine and idarubicin was helpful to reduce virus infection and improve patients' immunity. Another report on AML revealed that increasing $\mathrm{CD}^{+}{ }^{+} \mathrm{T}$ cells were represented in the AMLM5 subtype group compared with the AML-M3 group. Increased $\mathrm{CD} 8^{+} \mathrm{T}$ cells were associated with poor response [42]. The patients with chronic lymphocytic leukemia showed significantly higher percentage of $\mathrm{CD} 4^{+}$than that in healthy volunteers [43]. Guo et al. demonstrated that the patients with acute leukemia had higher absolute count of $\mathrm{CD}^{+}$compared with healthy controls, but with reduced immune function [44]. Xu et al. demonstrated that blocking the interaction between Tregs and AML cells may be a new approach to target leukemia stem cells in the treatment of AML [45]. There was a higher proportion of $\mathrm{CD} 4^{+} \mathrm{CD} 25^{+} \mathrm{CD} 127^{-} \mathrm{Foxp}^{+}$Tregs in newly diagnosed AML patients than healthy controls [46]. All these findings manifested $\mathrm{T}$ cells involved in immune response and mediated progress of disease. In addition, this study found that the incidence of adverse reactions in the study group was significantly lower than that in the control group. It suggested that idarubicin improved the safety of chemotherapy in AML patients due to its lower drug resistance and toxicity.

In summary, our data suggest that intravenous administration of cytarabine supplemented with idarubicin can improve the immune function and quality of life of AML patients, and this combination drug therapy is effective and safe for AML, which is worthy of clinical recommendation. However, limited numbers of AML patients in this study might lower the data reliability, and thus, further study should be carried out to confirm these findings.

\section{Data Availability}

The data used to support the findings of this study are included within the article.

\section{Conflicts of Interest}

The authors declare that they have no conflicts of interest.

\section{Acknowledgments}

The study was financially supported by the North Medicine and Functional Food Characteristic Subject Project in Heilongjiang Province (2018-TSXK-02).

\section{References}

[1] R. D. Brunning, "Classification of acute leukemias," Seminars in Diagnostic Pathology, vol. 20, no. 3, pp. 142-153, 2003.

[2] J. Prada-Arismendy, J. C. Arroyave, and S. Röthlisberger, "Molecular biomarkers in acute myeloid leukemia," Blood Reviews, vol. 31, no. 1, pp. 63-76, 2017.
[3] F. R. Appelbaum, H. Gundacker, D. R. Head et al., "Age and acute myeloid leukemia," Blood, vol. 107, no. 9, pp. 3481-3485, 2006.

[4] I. De Kouchkovsky and M. Abdul-Hay, "Acute myeloid leukemia: a comprehensive review and 2016 update," Blood Cancer Journal, vol. 6, no. 7, p. e441, 2016.

[5] E. M. Stein, C. D. DiNardo, D. A. Pollyea et al., "Enasidenib in mutant IDH2 relapsed or refractory acute myeloid leukemia," Blood, vol. 130, no. 6, pp. 722-731, 2017.

[6] L. Riva, L. Luzi, and P. G. Pelicci, "Genomics of acute myeloid leukemia: the next generation," Frontiers in Oncology, vol. 2, p. 40, 2012.

[7] J. Meyers, Y. Yu, J. A. Kaye, and K. L. Davis, "Medicare feefor-service enrollees with primary acute myeloid leukemia: an analysis of treatment patterns, survival, and healthcare resource utilization and costs," Applied Health Economics and Health Policy, vol. 11, no. 3, pp. 275-286, 2013.

[8] J. C. Byrd, K. Mrozek, R. K. Dodge et al., "Pretreatment cytogenetic abnormalities are predictive of induction success, cumulative incidence of relapse, and overall survival in adult patients with de novo acute myeloid leukemia: results from cancer and leukemia group B (CALGB 8461)," Blood, vol. 100, no. 13, pp. 4325-4336, 2002.

[9] G. Marcucci, K. Mrózek, and C. D. Bloomfield, "Molecular heterogeneity and prognostic biomarkers in adults with acute myeloid leukemia and normal cytogenetics," Current Opinion in Hematology, vol. 12, no. 1, pp. 68-75, 2005.

[10] K. Melgar, M. M. Walker, L. M. Jones et al., "Overcoming adaptive therapy resistance in AML by targeting immune response pathways," Science Translational Medicine, vol. 11, no. $508,2019$.

[11] M. T. Witkowski, A. Lasry, W. L. Carroll, and I. Aifantis, "Immune-based therapies in acute leukemia," Trends in Cancer, vol. 5, no. 10, pp. 604-618, 2019.

[12] A. Molodtsov and M. J. Turk, "Tissue resident CD8 memory T cell responses in cancer and autoimmunity," Frontiers in Immunology, vol. 9, p. 2810, 2018.

[13] M. A. Oberli, A. M. Reichmuth, J. R. Dorkin et al., "Lipid nanoparticle assisted mRNA delivery for potent cancer immunotherapy," Nano Letters, vol. 17, no. 3, pp. 1326-1335, 2017.

[14] A. Schiffrin, S. Suissa, G. Weitzner, P. Poussier, and D. Lalla, "Factors predicting course of $\beta$-cell function in IDDM," Diabetes Care, vol. 15, no. 8, pp. 997-1001, 1992.

[15] L. Ehlers, S. Rohde, S. Ibrahim, and R. Jaster, "Adoptive transfer of $\mathrm{CD}^{+}$T cells and $\mathrm{CD} 4^{+} \mathrm{CD} 44$ high memory T cells induces autoimmune pancreatitis in MRL/MpJ mice," Journal of Cellular and Molecular Medicine, vol. 22, no. 4, pp. 2404-2412, 2018.

[16] S. Sakaguchi, "Regulatory T cells: history and perspective," Regulatory T Cells, vol. 707, pp. 3-17, 2011.

[17] W. Li, R. Gao, T. Xin, and P. Gao, "Different expression levels of interleukin-35 in asthma phenotypes," Respiratory Research, vol. 21, no. 1, p. 89, 2020.

[18] L. Fotis, G. Agrogiannis, I. S. Vlachos et al., "Intercellular adhesion molecule (ICAM)-1 and vascular cell adhesion molecule (VCAM)-1 at the early stages of atherosclerosis in a rat model," Vivo, vol. 26, no. 2, pp. 243-250, 2012.

[19] H. Döhner, D. J. Weisdorf, and C. D. Bloomfield, "Acute myeloid leukemia," New England Journal of Medicine, vol. 373, no. 12, pp. 1136-1152, 2015.

[20] D. A. Pollyea, D. Bixby, A. Perl et al., "NCCN guidelines insights: acute myeloid leukemia, version 2.2021," Journal of the National Comprehensive Cancer Network, vol. 19, no. 1, pp. 16-27, 2021. 
[21] D. A. Arber, "The 2016 WHO classification of acute myeloid leukemia: what the practicing clinician needs to know," Seminars in Hematology, vol. 56, no. 2, pp. 90-95, 2019.

[22] T. M. Kadia, F. Ravandi, J. Cortes, and H. Kantarjian, "New drugs in acute myeloid leukemia," Annals of Oncology, vol. 27, no. 5, pp. 770-778, 2016.

[23] H. Döhner, E. H. Estey, S. Amadori et al., "Diagnosis and management of acute myeloid leukemia in adults: recommendations from an international expert panel, on behalf of the European leukemia net," Blood, vol. 115, no. 3, pp. 453-474, 2010.

[24] K. Saleh, N. Khalifeh-Saleh, and H. R. Kourie, "Acute myeloid leukemia transformed to a targetable disease," Future Oncology, vol. 16, no. 14, pp. 961-972, 2020.

[25] F. Ravandi, R. Assi, N. Daver et al., "Idarubicin, cytarabine, and nivolumab in patients with newly diagnosed acute myeloid leukaemia or high-risk myelodysplastic syndrome: a single-arm, phase 2 study," The Lancet Haematology, vol. 6, no. 9, pp. e480-e488, 2019.

[26] F. Arcamone, L. Bernardi, P. Giardino et al., "Synthesis and antitumor activity of 4-demethoxydaunorubicin, 4-demethoxy-7,9-diepidaunorubicin, and their beta anomers," Cancer Treatment Reviews, vol. 60, no. 7, pp. 829-834, 1976.

[27] H. Mizutani, C. Shiga, M. Imai et al., "Idarubicin, an anthracycline, induces oxidative DNA damage in the presence of copper (II)," Anticancer Research, vol. 40, no. 10, pp. 5399-5404, 2020.

[28] S. Adige, R. G. Lapidus, B. A. Carter-Cooper et al., "Equipotent doses of daunorubicin and idarubicin for AML: a meta-analysis of clinical trials versus in vitro estimation," Cancer Chemotherapy and Pharmacology, vol. 83, no. 6, pp. 1105-1112, 2019.

[29] B. Guiu, P. Chevallier, E. Assenat et al., "Idarubicin-loaded beads for chemoembolization of hepatocellular carcinoma: the IDASPHERE II single-arm phase II trial," Radiology, vol. 291, no. 3, pp. 801-808, 2019.

[30] D. Crivellari, D. Lombardi, G. Corona et al., "Innovative schedule of oral idarubicin in elderly patients with metastatic breast cancer: comprehensive results of a phase II multi-institutional study with pharmacokinetic drug monitoring," Annals of Oncology, vol. 17, no. 5, pp. 807-812, 2006.

[31] H. S. Howe, K. O. Kong, B. Y. Thong et al., "Urine sVCAM-1 and sICAM-1 levels are elevated in lupus nephritis," International Journal of Rheumatic Diseases, vol. 15, no. 1, pp. 13-16, 2012.

[32] H. Zaccagni, J. Fried, J. Cornell, P. Padilla, and R. L. Brey, "Soluble adhesion molecule levels, neuropsychiatric lupus and lupus-related damage," Frontiers in Bioscience, vol. 9, no. 1-3, pp. 1654-1659, 2004.

[33] V. S. Schellerer, M. C. Langheinrich, V. Zver et al., "Soluble intercellular adhesion molecule-1 is a prognostic marker in colorectal carcinoma," International Journal of Colorectal Disease, vol. 34, no. 2, pp. 309-317, 2019.

[34] S. Sak, M. Barut, A. Incebiyik et al., "Comparison of sVCAM-1 and sICAM-1 levels in maternal serum and vaginal secretion between pregnant women with preterm prelabour ruptures of membranes and healthy pregnant women," Journal of MaternalFetal and Neonatal Medicine, vol. 32, no. 6, pp. 910-915, 2019.

[35] L. Jimbu, O. Mesaros, A. Neaga et al., "The potential advantage of targeting both PD-L1/PD-L2/PD-1 and IL-10-IL10r pathways in acute myeloid leukemia," Pharmaceuticals (Basel), vol. 14, no. 11, 2021.

[36] G. Musuraca, S. De Matteis, R. Napolitano et al., "IL-17/IL-10 double-producing $\mathrm{T}$ cells: new link between infections, immunosuppression and acute myeloid leukemia," Journal of Translational Medicine, vol. 13, no. 1, p. 229, 2015.

[37] M. E. Turnis, D. V. Sawant, A. L. Szymczak-Workman et al., "Interleukin-35 limits anti-tumor immunity," Immunity, vol. 44, no. 2, pp. 316-329, 2016.

[38] Q. Tao, Y. Pan, Y. Wang et al., "Regulatory T cells-derived IL35 promotes the growth of adult acute myeloid leukemia blasts," International Journal of Cancer, vol. 137, no. 10, pp. 2384-2393, 2015.

[39] H. Wu, P. Li, N. Shao et al., "Aberrant expression of tregassociated cytokine IL-35 along with IL-10 and TGF- $\beta$ in acute myeloid leukemia," Oncology Letters, vol. 3, no. 5, pp. 1119-1123, 2012.

[40] C. Dong, "Cytokine regulation and function in T cells," Annual Review of Immunology, vol. 39, no. 1, pp. 51-76, 2021.

[41] H.-W. Mittrücker, A. Visekruna, and M. Huber, "Heterogeneity in the differentiation and function of $\mathrm{CD}^{+} \mathrm{T}$ cells," Archivum Immunologiae et Therapiae Experimentalis, vol. 62, no. 6, pp. 449-458, 2014.

[42] J. Huang, J. Tan, Y. Chen et al., "A skewed distribution and increased PD- $1+\mathrm{V} \beta+\mathrm{CD}^{4}+/ \mathrm{CD}^{8}+\mathrm{T}$ cells in patients with acute myeloid leukemia," Journal of Leukocyte Biology, vol. 106, no. 3, pp. 725-732, 2019.

[43] E. Allahmoradi, S. Taghiloo, M. Tehrani et al., "CD4 ${ }^{+} \mathrm{T}$ cells are exhausted and show functional defects in chronic lymphocytic leukemia," Iranian Journal of Immunology, vol. 14, no. 4, pp. 257-269, 2017.

[44] W. Guo, C. Xing, A. Dong et al., "Numbers and cytotoxicities of $\mathrm{CD}^{+} \mathrm{CD}^{2} 6^{+} \mathrm{T}$ lymphocytes in peripheral blood of patients with acute myeloid leukemia and acute lymphocytic leukemia," Cancer Biology \& Therapy, vol. 14, no. 10, pp. 916-921, 2013.

[45] Y. Xu, J. Mou, Y. Wang et al., "Regulatory T cells promote the stemness of leukemia stem cells through IL10 cytokine-related signaling pathway," Leukemia, vol. 36, no. 2, pp. 403-415, 2022.

[46] Q. Dong, G. Li, C. Fozza et al., "Levels and clinical significance of regulatory B cells and T cells in acute myeloid leukemia," BioMed Research International, vol. 2020, Article ID 7023168, 6 pages, 2020. 